\section{Peningkatan Kemampuan \\ Membaca Bahasa Jerman \\ Melalui Metode Active Learning Tipe Reading Guide}

\author{
St. Nur Rahmah Irfan' ${ }^{1}$ dan Hasmawati ${ }^{2}$ \\ Fakultas Bahasa dan Sastra \\ Universitas Negeri Makassar \\ Email: hasmawati@unm.ac.id²
}

http://ojs.unm.ac.id/index.php/Insani/index

Abstrak. Tujuan penelitian ini adalah untuk memeroleh data perencanaan, proses, dan hasil metode active learning tipe reading guide dalam kemampuan membaca bahasa Jerman siswa. Data penelitian ini adalah data kualitatif dan data kuantitatif. Data kualitatif diperoleh melalui observasi dan data kuantitatif diperoleh melalui tes kemampuan membaca siklus I dan siklus II. Data dianalisis dengan menggunakan teknik persentase. Hasil penelitian ini menunjukkan bahwa kemampuan membaca dengan persentase nilai yang diperoleh siswa pada siklus I mencapai $66,78 \%$ dan siklus II mencapai $82,14 \%$. Hasil ini menunjukkan bahwa metode active learning tipe reading guide dapat meningkatkan kemampuan membaca bahasa Jerman siswa.

Kata Kunci: Active Learning, Kemampuan Membaca, Bahasa Jerman

\section{INDONESIAN \\ JOURNAL OF \\ EDUCATIONAL \\ STUDIES (IJES)}

\section{E-ISSN: 2621-6744 \\ P-ISSN: 2621-6736}

Submitted: June, $1^{\text {st }} 2018$

Accepted : June, $24^{\text {th }} 2018$

Abstract. The purpose of this study was to obtain data on planning, process, and results of the reading guide type active learning method in students' German reading skills. The data of this study are qualitative data and quantitative data. Qualitative data is obtained through observations and quantitative data obtained through the ability to read the cycle I and cycle II. Data were analyzed using percentage techniques. The results of this study indicate that the reading ability with the percentage value obtained by students in the first cycle reached $66.78 \%$ and the second cycle reached $82.14 \%$. These results indicate that the active learning type of reading guide can improve students' reading skills. 


\section{PENDAHULUAN}

Bahasa asing telah menjadi salah satu mata pelajaran pilihan yang diajarkan di Sekolah Menengah Atas (SMA), Sekolah Menengah Kejuruan (SMK), maupun Madrasah Aliyah (MA). Salah satu bahasa asing yang dipelajari di sekolah adalah bahasa Jerman. Bahasa Jerman perlu dipelajari karena bahasa Jerman merupakan bahasa yang penting dalam komunikasi internasional disamping bahasa Inggris. Bahasa Jerman menempati kedudukan kuat dalam pengetahuan, teknologi maupun sastra dan mempunyai peran penting dalam penelitian dan pendidikan. Bahasa Jerman merupakan bahasa ibu yang paling banyak penuturnya dan termasuk kesepuluh bahasa yang paling banyak digunakan di Eropa (Tatsachen über Deutschland, 2015:7).

Berdasarkan hasil observasi yang dilakukan di SMAN 14 Gowa menunjukkan bahwa kemampuan siswa dalam berbahasa Jerman pada kelas XI khususnya pada kemampuan membaca masih belum optimal. Banyak siswa kesulitan untuk memahami isi teks karena minimnya penguasaan kosakata bahasa Jerman. Mereka belum dapat memahami teks dengan baik, mengartikan teks kata per kata tanpa mengetahui konteks bacaan dan keaktifan dalam mengikuti pembelajaran belum maksimal. Faktor lain yang dapat mempengaruhi rendahnya kemampuan membaca bahasa Jerman adalah metode pembelajaran membaca yang dipakai oleh guru belum tepat dan efisien. Guru sebaiknya menggunakan metode pembelajaran yang menarik dan bervariasi untuk mengatasi kelemahan siswa dalam pembelajaran membaca bahasa Jerman. Metode pembelajaran yang bervariasi penting dilakukan oleh guru agar dapat memudahkan siswa dalam pembelajaran membaca bahasa Jerman.

Rendahnya kemampuan siswa dalam memahami teks bahasa Jerman didukung oleh hasil penelitian yang telah dilakukan oleh Indah (2014:48) menunjukkan bahwa kemampuan membaca memahami teks bahasa Jerman siswa XI SMA Negeri 3 Makassar tergolong dalam kategori rendah, (51,66\%). Sementara hasil penelitian yang dilakukan oleh Muslim (2012:45) menunjukkan bahwa kemampuan membaca memahami bahasa Jermana siswa kelas XI IPA SMA Negeri 2 Bontotiro Kabupaten Bulukumba tergolong dalam kategori rendah, (38,24\%). Berdasarkan uraian tersebut, peneliti mencoba untuk mengatasi hal tersebut dengan menerapkan metode active learning tipe reading guide. Metode ini belum pernah diterapkan dalam proses pembelajaran bahasa Jerman untuk meningkatkan kemampuan membaca bahasa Jerman pada siswa dan didukung oleh hasil penelitian yang telah dilakukan oleh Munir (2011:58) yang menggunakan metode reading guide dalam pembelajaran Al-Qur'an Hadist kelas XI IPS 1 di MA NU Hasyim Asy'ari 03 Kudus tergolong dalam kategori baik, yaitu 78,94\%.

Metode pembelajaran aktif (active learning) merupakan metode yang bentuk pembelajarannya memungkinkan siswa berperan secara aktif dalam proses pembelajaran itu sendiri baik dalam bentuk interaksi antar siswa maupun siswa dengan guru dalam proses pembelajaran. Metode active learning memiliki berbagai macam tipe, salah satunya adalah membaca terbimbing (reading guide). Membaca terbimbing (reading guide) merupakan metode yang mengajak siswa untuk mempelajari sesuatu dengan cara membaca suatu bacaan sesuai dengan materi pembelajaran. Agar proses membaca ini bisa efektif, maka guru memberikan 
pedoman (guide) membaca. Pedoman ini berisi pertanyaan-pertanyaan yang harus dijawab siswa berdasarkan isi bacaan, bisa berisi tugas-tugas yang harus dilakukan siswa dalam pembelajaran. Kegiatan membaca secara terbimbing akan memudahkan siswa untuk fokus dalam memahami pelajaran yang disampaikan oleh guru.

Menurut Silberman (2016:9) belajar bukan merupakan konsekuensi otomatis dari penyampaian informasi kepada siswa. Belajar membutuhkan keterlibatan mental dan tindakan sekaligus. Pada saat kegiatan belajar itu aktif, siswa melakukan sebagian besar pekerjaan belajar. Mereka mempelajari gagasan-gagasan, memecahkan berbagai masalah dan menerapkan apa yang mereka pelajari. Senada dengan Silberman, Harasim (2017:71) mengemukakan bahwa "Active learning means encouraging students to participate and act, such as conducting a real experiment, rather than learn passively (listening to a lecture, reading a book)". Hal tersebut berarti pembelajaran aktif merupakan pembelajaran yang mendorong siswa untuk berpartisipasi dan bertindak, seperti melakuan kegiatan, daripada belajar secara pasif (hanya mendengarkan ceramah dan membaca buku).

Selanjutnya, menurut Mukrimaa (2014:107) "Pembelajaran aktif (active learning) adalah suatu proses pembelajaran untuk memberdayakan peserta didik agar belajar dengan menggunakan berbagai cara/strategi secara aktif". Selanjutnya Hardini dan Puspitasari (2012:83) berpendapat bahwa "Pembelajaran aktif merupakan suatu pendekatan pembelajaran yang lebih banyak melibatkan aktivitas peserta didik dalam mengakses berbagai informasi dan pengetahuan untuk dibahas dan dikaji dalam pembelajaran di kelas sehingga mereka mendapatkan berbagai pengalaman yang dapat meningkatkan pemahaman dan kompetensinya". Senada dengan Hardini dan Puspitasari, Zaini (2017:xvi) menyatakan bahwa "Pembelajaran aktif adalah suatu pembelajaran yang mengajak siswa untuk belajar secara aktif dalam semua proses pembelajaran, tidak hanya mental akan tetapi juga melibatkan fisik". Berdasarkan beberapa pendapat tersebut, dapat disimpulkan bahwa active learning (pembelajaran aktif) adalah segala bentuk pembelajaran yang memungkinkan siswa berperan secara aktif dalam proses pembelajaran itu sendiri baik dalam bentuk interaksi antar siswa maupun siswa dengan guru dalam proses pembelajaran.

\section{METODE PENELITIAN}

Penelitian ini merupakan penelitian tindakan kelas (Classroom Action Research). Penelitian tindakan dilakukan untuk meningkatkan aktivitas pembelajaran bahasa Jerman melalui metode active learning tipe reading guide. Model yang digunakan dalam penelitian ini adalah Model Hopkins dengan beberapa tahapan, yaitu perencanaan, pelaksanaan, pengamatan, analisis data pada tahapan refleksi dan yang terakhir adalah hasil analisis data. Tahapan-tahapan pada penelitian tindakan kelas model Hopkins tersebut dimaksudkan agar dapat memberikan gambaran yang jelas mengenai peningkatan kemampuan membaca bahasa Jerman siswa kelas XI SMAN 14 Gowa.

Penelitian ini dilaksanakan di SMAN 14 Gowa, yang berlokasi di Jl. Malino No.191, Batangkaluku, Somba Opu, Kabupaten Gowa, Provinsi Sulawesi Selatan, kode pos 92112. Sekolah ini memiliki luas $8.083 \mathrm{Ha}$ dengan jumlah ruangan 30. Subjek dalam penelitian ini adalah siswa kelas XI IPS 1 SMAN 14 Gowa yang berjumlah 28 siswa 
dengan fokus penelitian adalah kemampuan membaca dengan menggunakan metode active learning tipe reading guide. Instrumen yang digunakan dalam penelitian ini adalah lembar observasi dan tes hasil belajar siswa. Tes digunakan untuk mengukur tingkat keberhasilan siswa dalam belajar sekaligus mengukur keberhasilan program pembelajaran. Adapun lembar observasi yang digunakan adalah lembar observasi untuk guru dan siswa.

Penelitian tindakan kelas ini terdiri atas dua siklus dengan dua kali pertemuan tiap siklus, dimana kedua siklus tersebut merupakan rangkaian yang saling berkaitan. Artinya, pelaksanaan siklus II merupakan lanjutan dan perbaikan dari pelaksanaan siklus I. Untuk mengetahui kegiatan pembelajaran menggunakan metode active learning tipe reading guide dalam kemampuan membaca bahasa Jerman siswa kelas XI SMAN 14 Gowa, maka dapat dilihat dari hasil tes membaca dari tiap siklus dan lembar observasi siswa yang berisi kegiatan-kegiatan dan tingkah laku siswa di kelas selama proses pembelajaran berlangsung.

\section{HASIL DAN PEMBAHASAN}

\section{Deskripsi Hasil Tes Kemampuan Membaca Siswa pada Siklus I}

Hasil tes kemampuan membaca bahasa Jerman siswa kelas XI IPS 1 menunjukkan bahwa masih banyak siswa belum mampu menjawab soal-soal dengan tepat baik pilihan ganda, benar-salah (richtig-falsch), dan tes menjodohkan. Hal tersebut dipicu karena kurangnya kosakata siswa. Suasana kelas yang sangat ribut menyebabkan siswa yang lain kurang fokus menjawab soal-soal yang diberikan guru. Data hasil kemampuan membaca bahasa Jerman siswa kelas XI IPS 1 SMAN 14 Gowa terdapat pada lampiran halaman 96. Berdasarkan data yang diperoleh dapat disimpulkan bahwa jumlah siswa sebanyak 28 siswa pada siklus I. Adapun nilai terendah yang didapatkan siswa dalam kemampuan membaca bahasa Jerman adalah 50 sedangkan siswa mendapatkan nilai tertinggi yaitu 90.

Untuk mencari skor rata-rata kemampuan membaca bahasa Jerman siswa, maka digunakan rumus sebagai berikut:

$$
\begin{aligned}
\text { Skor rata-rata } & =\frac{\sum \text { Nilai }}{\sum \text { Peserta }} \\
& =\frac{1870}{28}=66,78
\end{aligned}
$$

Setelah mengetahui skor rata-rata siswa, selanjutnya mencari persentase dengan menggunakan rumus sebagai berikut:

$$
\begin{aligned}
\text { Persentase } & =\frac{\text { Jumlah Skor yang diperoleh }}{\text { Jumlah Skor Maksimum }} \times 100 \% \\
& =\frac{1870}{28} \times 100 \%=66,78 \%
\end{aligned}
$$

Untuk menentukan jumlah kelas interval (K), maka rumus yang digunakan adalah $1+(3,3) \log n$, di mana $n$ adalah jumlah peserta di kelas yakni terdapat 28 siswa. Log $n$ yaitu $\log 28=1,44$. Hasil yang didapatkan untuk kelas interval (K) adalah $1+3,3$ $(1,44)=5,75$ atau 6 . Selanjutnya, untuk mencari rentangan $(R)$ digunakan rumus nilai tertinggi (h) - nilai terendah (I) : kelas interval (K). Hasil yang didapatkan adalah 90 $50: 6=6,66$. Maka, besar rentangan yang didapatkan adalah 6,66 dibulatkan menjadi 7. 
Tabel 1.

Data Frekuensi dan Persentase Kemampuan Membaca Bahasa Jerman Siklus I

\begin{tabular}{cccc}
\hline No & Kelas Interval & Frekuensi & Persentase \\
\hline 1 & $50-56$ & 5 & $17,85 \%$ \\
\hline 2 & $57-63$ & 6 & $21,42 \%$ \\
\hline 3 & $64-70$ & 5 & $17,85 \%$ \\
\hline 4 & $71-77$ & 8 & $28,57 \%$ \\
\hline 5 & $78-84$ & 2 & $7,14 \%$ \\
\hline 6 & $85-91$ & 2 & $7,14 \%$ \\
\hline & Jumlah & 28 & $100 \%$ \\
\hline
\end{tabular}

Berdasarkan data pada tabel di atas, maka dapat diketahui bahwa kemampuan membaca bahasa Jerman siswa dengan menggunakan metode active learning tipe reading guide dengan tingkat persentase $17,85 \%$ yang termasuk dalam kelas interval 50-56 adalah 5 orang. Sementara itu, siswa dengan tingkat persentase $21,42 \%$ yang termasuk dalam kelas interval $57-63$ sebanyak 6 orang. Selanjutnya, siswa yang memiliki tingkat persentase $17,85 \%$ dan termasuk dalam kelas interval $64-70$ sebanyak 5 orang. Kemudian, siswa yang memiliki tingkat persentase $28,57 \%$ yang termasuk dalam kelas interval 71-77 sebanyak 8 orang, Siswa yang memiliki tingkat persentase $7,14 \%$ dan termasuk dalam kelas interval $78-84$ sebanyak 2 orang serta siswa yang memiliki tingkat persentase $7,14 \%$ dan termasuk dalam kelas interval $85-91$ sebanyak 2 orang.

\section{Deskripsi Hasil Tes Kemampuan Membaca Siswa pada Siklus II}

Evaluasi siklus II dilaksanakan pada tanggal Mei 2018. Hasil tes kemampuan membaca bahasa Jerman siswa kelas XI IPS 1 menunjukkan bahwa siswa mengerjakan soal-soal dengan fokus dan tenang baik pilihan ganda, benar-salah (richtig-falsch), dan tes menjodohkan. Pemahaman materi bacaan yang diberikan pada siklus II cukup baik. Siswa bersemangat mencari kosakata yang merupakan hal baru diketahui. Data hasil kemampuan membaca bahasa Jerman siswa kelas XI IPS 1 SMAN 14 Gowa terdapat pada lampiran halaman 97. Berdasarkan data yang diperoleh dapat disimpulkan bahwa jumlah siswa sebanyak 28 siswa pada siklus I. Adapun nilai terendah yang didapatkan siswa dalam kemampuan membaca bahasa Jerman adalah 50 sedangkan siswa mendapatkan nilai tertinggi yaitu 90. Untuk mencari skor ratarata kemampuan membaca bahasa Jerman siswa, maka digunakan rumus sebagai berikut:

Skor rata-rata $\quad=\frac{\sum \text { Nilai }}{\sum_{2300} \text { Peserta }}$

$$
=\frac{2300}{28}=82,14
$$

Setelah mengetahui skor rata-rata siswa, selanjutnya mencari persentase dengan menggunakan rumus sebagai berikut:

$$
\begin{aligned}
\text { Persentase } & =\frac{\text { Jumlah Skor yang diperoleh }}{\text { Jumlah Skor Maksimum }} \times 100 \% \\
& =\frac{2300}{28} \times 100 \%=82,14 \%
\end{aligned}
$$


Untuk menentukan jumlah kelas interval (K), maka rumus yang digunakan adalah $1+(3,3) \log n$, dimana $n$ adalah jumlah peserta di kelas yakni terdapat 28 siswa. Log $n$ yaitu $\log 28=1,44$. Hasil yang didapatkan untuk kelas interval (K) adalah $1+3,3$ $(1,44)=5,75$ atau 6 . Selanjutnya, untuk mencari rentangan $(R)$ digunakan rumus nilai tertinggi ( $(\mathrm{h})$ - nilai terendah ( $\mathrm{I}$ ) : kelas interval (K). Hasil yang didapatkan adalah 97 $70: 6=4,5$ dibulatkan menjadi 5 . Maka, besar rentangan yang didapatkan adalah 5 .

Tabel 2.

Data Frekuensi dan Persentase Kemampuan Membaca Bahasa Jerman Siklus II

\begin{tabular}{cccc}
\hline No & Kelas Interval & Frekuensi & Persentase \\
\hline 1 & $70-74$ & 5 & $17,85 \%$ \\
\hline 2 & $75-79$ & 4 & $14,28 \%$ \\
\hline 3 & $80-84$ & 9 & $32,14 \%$ \\
\hline 4 & $85-89$ & 4 & $14,28 \%$ \\
\hline 5 & $90-94$ & 5 & $17,85 \%$ \\
\hline 6 & $95-99$ & 1 & $3,57 \%$ \\
\hline & Jumlah & 28 & $100 \%$ \\
\hline
\end{tabular}

Berdasarkan data pada tabel di atas, maka dapat diketahui bahwa kemampuan membaca bahasa Jerman siswa dengan menggunakan metode active learning tipe reading guide dengan tingkat persentase $17,85 \%$ yang termasuk dalam kelas interval 70-74 adalah 5 orang. Sementara itu, siswa dengan tingkat persentase $14,28 \%$ yang termasuk dalam kelas interval $75-79$ sebanyak 4 orang. Selanjutnya, siswa yang memiliki tingkat persentase $32,14 \%$ dan termasuk dalam kelas interval $80-84$ sebanyak 9 orang. Kemudian, siswa yang memiliki tingkat persentase $14,28 \%$ yang termasuk dalam kelas interval 85-89 sebanyak 4 orang, Siswa yang memiliki tingkat persentase $17,85 \%$ dan termasuk dalam kelas interval 90-94 sebanyak 5 orang serta siswa yang memiliki tingkat persentase 3,57\% dan termasuk dalam kelas interval 9599 sebanyak 1 orang.

\section{KESIMPULAN}

Berdasarkan hasil penelitian dan pembahasan yang dilakukan maka dapat disimpulkan bahwa:

1. Perencanaan pembelajaran dalam kemampuan membaca bahasa Jerman melalui metode active learning tipe reading guide siswa kelas XI SMAN 14 Gowa telah terlaksana dengan baik yang terdiri atas beberapa aspek, yaitu melalui rencana pelaksanaan pembelajaran (RPP), sumber belajar yang berupa buku Deutsch ist einfach, pembuatan instrumen kemampuan membaca bahasa Jerman, serta lembar observasi guru dan siswa.

2. Proses pembelajaran kemampuan membaca bahasa Jerman siswa kelas XI IPS 1 SMAN 14 Gowa mengalami peningkatan baik, dari segi kognitif maupun afektif siswa.

3. Hasil evaluasi kemampuan membaca bahasa Jerman siswa kelas XI IPS 1 SMAN 14 Gowa melalui metode active learning tipe reading guide dinyatakan meningkat, hal ini dibuktikan dengan nilai rata-rata pada siklus I yaitu 66,78 
sedangkan nilai rata-rata pada siklus II mencapai 82,14 dengan perbandingan skor rentangan yang diperoleh antara sikus I dan siklus II yaitu 15,36.

\section{DAFTAR PUSTAKA}

Hardini, Isriani dan Puspitasari, Dewi. (2012). Strategi Pembelajaran Terpadu. Yogyakarta: Familia.

Indah, Nur. (2014). Kemampuan Membaca Memahami Teks Bahasa Jerman Siswa XI SMA Negeri 3 Makassar. Skripsi. Makassar: Universitas Negeri Makassar.

Mukrimaa, Syifa S. (2014). 53 Metode Belajar dan Pembelajaran. Bandung: Universitas Pendidikan Indonesia.

Munir, Muhammad Misbahul. (2011). Upaya Meningkatkan Prestasi Belajar Peserta Didik Dengan Penggunaan Metode Reading Guide Dalam Pembelajaran AlQur'an Hadis Pokok Bahasan Berkompetisi Dalam Kebaikan Kelas XI IPS 1 Di MA NU Hasyim Asy'ari 03 Kudus 2010/ 2011. Skripsi. Semarang: Institut Agama Islam Negeri Walisongo.

Muslim, Rismayanti. (2012). Hubungan Penguasaan Kosakata dengan Kemampuan Membaca Memahami Siswa Kelas XI IPA SMA Negeri 2 Bontotiro Kabupaten Bulukumba. Skripsi. Makassar: Universitas Negeri Makassar.

Silberman, Melvin L. (2016). Active Learning 101 Cara Belajar Siswa Aktif. Bandung: Nuansa Cendekia. 